\section{Laser hair removal a risky business in need of regulation, experts say}

Previously published at www.cmaj.ca

$\infty \quad$ See related editorial, page 743

$\mathrm{D}$ ermatologist Dr. Vince Bertucci has seen patients with permanent disfigurement, skin discolouration and burns as a result of complications from laser hair removal - a procedure largely unregulated in Canada.

"I just saw a young girl - it was a very sad case - who developed a very prominent scar on her right upper lip from laser hair removal. She's under 20 years old," says Bertucci, a consultant dermatologist at Women's College Hospital and former codirector of undergraduate dermatology at the University of Toronto in Ontario. "It's heart-wrenching to deal with these cases because ... they're going in to look better, and come out looking worse."

There is always a risk of complications, even when a medical doctor performs the procedure, adds Bertucci, who is also past president of the Canadian Society for Dermatologic Surgery and medical director of Bertucci MedSpa in Woodbridge, Ontario.

But the risk is magnified when laser hair removal is performed by people with no medical training and no physician is on site in case things go wrong, he says.

Health Canada says it regulates laser devices to ensure that systems sold in Canada are "safe and effective when used for their licenced medical purposes by trained professionals according to the manufacturers' directions" (www.hc-sc .gc.ca/hl-vs/iyh-vsv/med/laser-eng.php).

However, there is no stipulation as to who can actually use these devices for cosmetic laser hair removal. Nor are there federal or provincial training requirements.

In the United States, more than half of state governments now stipulate that electrologists, cosmetologists, estheticians and other nonmedical personnel may not perform laser hair removal without on-site medical supervision, according to the American Society for Dermatologic Surgery, which takes the position that such procedures should only be done under the supervision of a medical doctor with extensive training in laser surgery techniques.

The United Kingdom permits nonmedical personnel, such as beauticians, to perform laser hair removal, but they are legally required to register with the Department of Health's Care Quality Commission to ensure that minimum training and safety standards are met. The commission has even prosecuted a health spa owner for operating hair removal lasers without registration.

By contrast, Health Canada, merely states in a consumer advisory about cosmetic laser treatments that "experts in cosmetics with proper training in laser techniques should be able to perform hair reduction treatments with minimal risks to the Canadian public. For any other type of laser treatment, Health Canada advises you to seek the services of a licenced health care professional with specialized training in laser procedures."

Canadian regulation is "lagging," Bertucci says. "I think it's a matter of time."

Although the National Law Journal says that in the US, complications involving laser hair removal and other procedures at medical spas are becoming a "litigation hot spot," (www.law .com/jsp/article.jsp?id=1202433518513), lawsuits in Canada have been rare. Among the few that have been filed is one that was withdrawn involving a British Columbia woman who claimed laser hair removal caused her to grow a beard.

A Health Canada spokesman said the government has received no complaints about adverse events or reactions regarding laser hair removal devices.

But "if you have been in practice long enough, you'll always see complications," Bertucci says. "And complications can happen to anybody."

Bertucci adds that the question that invariably arises when physicians push for more regulation is whether laser hair removal is, in fact, a medical procedure involving a medical device, or a
Looking for sustained power?

\section{Look at HUMIRA for Crohn's disease}

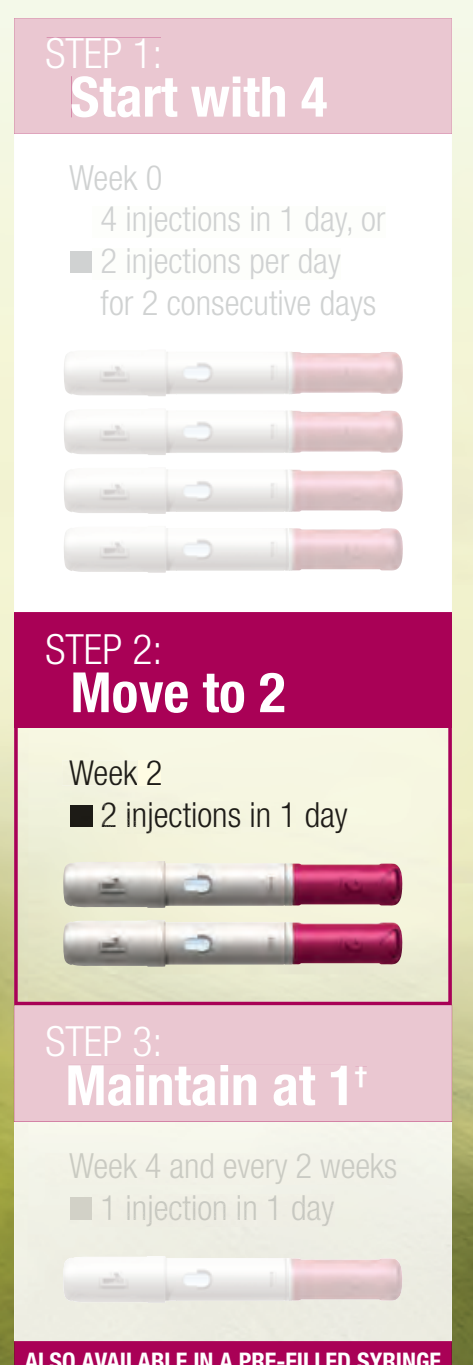

HUMIRA every 2 weeks.

Sustained power

with subcutaneous

self-injection. ${ }^{\dagger}$

t The use of HUMIRA in CD beyond one year has

not been evaluated in controlled clinical studies

\section{HUMIRA}

Abbott 


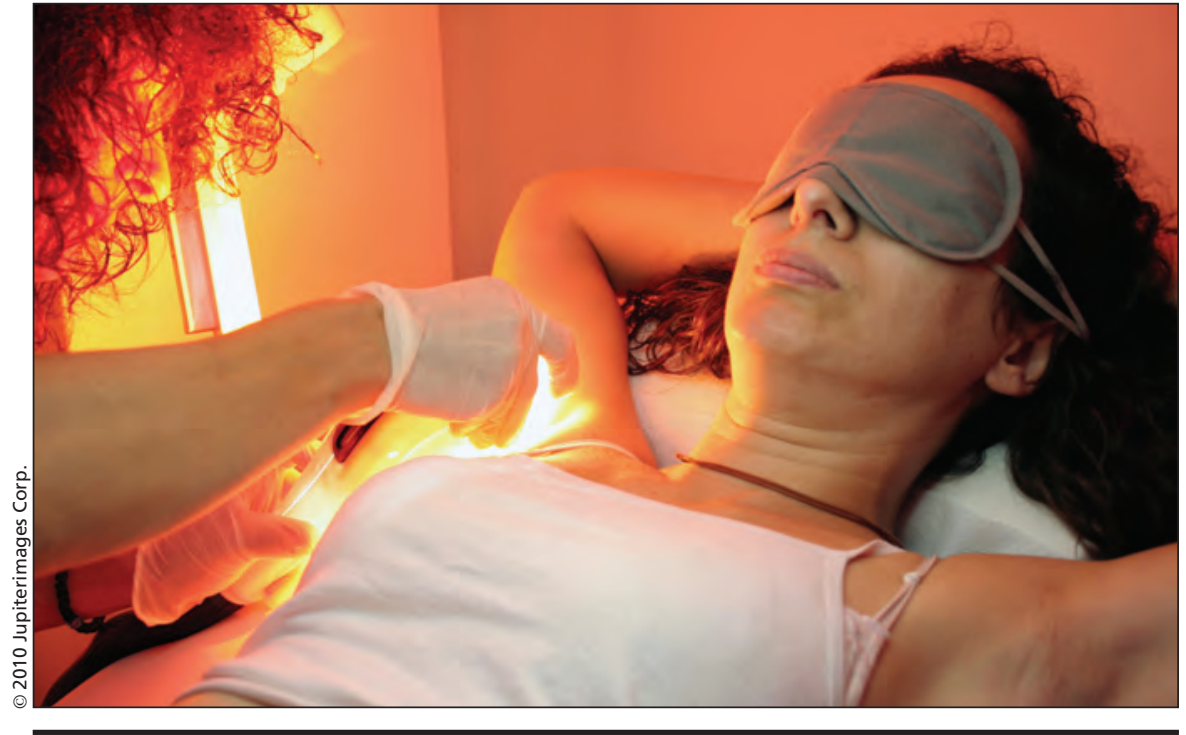

A beautician removes hair from the underarm of a client.

low-risk operation that does not require extensive medical knowledge.

Hamilton, Ontario-based dermatologist Dr. Peter Vignjevic says lasers fall into the former category. "I don't think you have to be a brain surgeon to operate a laser, and I don't believe that you need to be a nurse to be able to operate a laser. But the concern I have is that, because there is no regulation, pretty much anyone and everyone can operate a laser which I don't think is right, either."

In British Columbia, the owners of establishments that offer laser hair removal are required to appoint laser safety officers, to train staff and to ensure that they "operate their establishments in a way that prevents health hazards from occurring."
Neither the BC nor the Ontario government says it has a record of complaints involving laser hair removal, while Alberta does not keep statistics.

Even the Canadian Dermatology Association has not adopted a formal position on the need for more regulation. But Bertucci expects the issue to surface at the association's annual meeting this summer, Bertucci says. "I would suggest that anything you are doing to someone else that has a potential to cause disfigurement and other problems and complications - and that influences the skin other than just the top layer, which laser hair removal does - should be considered the practice of medicine."

Dr. Edward Zimmerman, a Las Vegas, Nevada-based cosmetic surgeon and president of the American Board of Laser Surgery, says laser systems target the melanin in the hair follicle and when the procedure is done properly, the heat inactivates or destroys cells in the target area without having a significant effect on surrounding cells, Zimmerman says. The problem is, "the ideal patient never walks through the door."

"There is always some nuance, there is always some photosensitizer that they [the patient] forgot to tell you about," adds Zimmerman, who advocates more training of physicians on medical laser techniques and greater supervision of procedures performed by nonmedical operators.

"You need somebody who is familiar enough with lasers and how they work to say, 'these are the settings we should use today.' Or perhaps we shouldn't do it today if they have been on one of the many photosensitizers out there - everything from blood pressure medicines, to antibiotics, even ginko, garlic and ginger, things like that," he says. "I think it's a little more often than not the nonphysicians who are getting into trouble because they're using cookie-cutter settings to treat everyone who walks in the door."

"For instance, somebody on St. John's Wort can be enormously photosensitive ... so the setting that worked on them the last time, will now turn them into a crispy critter, with the potential of burns and scars," Zimmerman adds. - Virginia Galt, Toronto, Ont.

DOI:10.1503/cmaj.109-3230

\section{More news at www.cmaj.ca}

\begin{abstract}
Military ombudsman to again review mental health services: National Defence and Canadian Forces Ombudsman Pierre Daigle will conduct a follow-up review of a 2008 investigation into military mental health services that found that too many soldiers with operational stress injuries were slipping through cracks in the system. - Roger Collier, CMAJ
\end{abstract}

Electronic health records a "strong priority" for US government: Under legislation passed last year, the US government will invest as much as US $\$ 27$ billion in recently launched incentives aimed at encouraging physicians to abandon their paperwork and join the information age. - Paul Christopher Webster, Toronto, Ont.

Obama breaks a century's logjam: Health reform change in the United States looks like a supersized jigsaw puzzle. Ahead is a complex system of subsidies, regulations and new insurance markets aimed at extending health care to 32 million uninsured citizens and making it more affordable and secure for the rest. The US is taking a much different road than Canada toward the same destination. - Cal Woodward, Washington, DC

US health reform heads for legal showdown with states: In a broad offensive, Republican officials in 14 US states swiftly launched lawsuits in 